\title{
Elisa de captura com IgY para quantificação de acetato de lupeol em Vernonia scorpioides lam. Pers (asteraceae)
}

\author{
Capture IgY-Elisa to quantify lupeol acetate in Vernonia scorpioides lam. Pers (asteraceae)
}

\author{
Ronald Bastos Freire ${ }^{1}$ Márcia de Fátima Inácio Freire ${ }^{2}$ Ricardo Louro Berbara ${ }^{3}$
}

\section{RESUMO}

O presente experimento descreve, pela primeira vez, a elaboração de um ensaio imunoenzimático (ELISA de captura) com anticorpos IgY para a detecção e quantificação de acetato de lupeol (LAc) em Vernonia scorpioides Lam. Pers (Asteraceae). Anticorpos anti-LAc, obtidos partir do soro das aves e gemas de seus ovos, após imunização com o conjugado acetato de lupeol-cBSA, foram concentrados em coluna contendo LAc-BSA acoplado a sepharose. A eficácia da metodologia de detecção imunológica foi de 97\%, com índices de sensibilidade e especificidade de $99 \%$ e 95\%, respectivamente com limites de detecção do ensaio entre $0,02 \mu \mathrm{g} . \mathrm{g}^{-1}$ (inferior) e $10 \mu \mathrm{g} \mathrm{g}^{-1}$ (superior). A robustez do método foi atestada pela sua elevada reprodutibilidade (entre $94,75 \%$ e $96,81 \%)$, e pelo baixo coeficiente de variação interna $(4,22 \pm$ $1,03 \%)$ nas condições de execução descritas.

Palavras-chave: IgY-ELISA, IgY, Vernonia scorpioides, acetato de lupeol, controle de qualidade vegetal.

\section{ABSTRACT}

For the first time, a yolk immunoglobulins-based immunenzymatic assay (capture IgY-ELISA) was carried out to detect Lupeol acetate (LAc) from Vernonia scorpioides Lam. Pers (Asteraceae). Antibodies (IgY) against lupeol acetate (antiLAc antibodies) were raised in White Leghorn hens immunized with LAc conjugated to the bovine serum albumin ( $L A c-B S A)$. The anti-LAc antibodies were recovered by cleanup columns containing LAc-BSA coupled to sepharose. The capture IgYELISA efficacy was of $97 \%$ when the predictive indices of sensitivity and specificity were $99.0 \%$ and $95 \%$, respectively. The lowest and highest detection limits were of $0.02 \mu \mathrm{gg}^{-1}$ and $10 \mu \mathrm{gg}^{-1}$ of plant extract, respectively. The strength of this method was attested by its high reproducibility (between $94.75 \%$ and $96.81 \%)$, and a low internal variation (4.22 $\pm 1.03 \%)$, under the described conditions.

Key words: IgY-ELISA, IgY, Vernonia scorpioides, lupeol acetate, vegetal quality control.

\section{INTRODUÇÃO}

A utilização crescente de produtos naturais torna essencial o desenvolvimento de métodos analíticos com elevada especificidade, sensibilidade e reprodutibilidade para que a sua certificação e eficácia sejam garantidas (CONNORS, 1982). Nas últimas décadas, diversos pesquisadores em todo o mundo têm desenvolvido experimentos acerca da possibilidade de se desenvolver anticorpos de galinhas poedeiras (IgY) para capturar micromoléculas haptênicas, tais como antibióticos, pesticidas, herbicidas e metabólitos secundários característicos de animais e vegetais (POLSON, 1990; FREIRE, 1994, HERMANSON, 1996; WELZIG, 2003). Uma vez que os anticorpos IgY têm sido considerados uma ferramenta barata e conveniente para imunoterapias e imunodiagnósticos, podem, também, ser utilizados para o controle de qualidade de plantas medicinais. A captura imunológica de princípios ativos é um processo pouco explorado de biotecnologia avançada, embora haja sugestões de que seja capaz de simplificar e ampliar os métodos de "screening" que permitam uma fácil, rápida e extensa qualificação de princípios ativos em plantas (CIBOTTI, 1990). Dadas as suas diferenças evolucionárias, as IgY, além de serem facilmente obtidas a partir de gemas de ovos, não interagem com a proteína A de Staphylococcus aureus, são mais resistentes à proteólise, a temperaturas mais elevadas e são capazes de reconhecer, com facilidade, epítopos antigênicos de imunogenicidade insignificante para mamíferos (POLSON, 1990). No presente trabalho, ava-

${ }^{1}$ Farmacêutico-bioquímico, Professor Adjunto, PhD em Medicina Veterinária, Departamento de Biologia Animal, Instituto de Biologia, Universidade Federal Rural do Rio de Janeiro (UFRRJ), BR 465, Km 7, 23851-900, Seropédica, RJ. E-mail: rbfreire@ ufrrj.br. Autor para corespondência.

${ }^{2}$ Engenheiro Florestal, Fitossanitarista, PhD em Agronomia, Setor de Conservação e Manutenção de Área Verde, Instituto de Pesquisas Jardim Botânico do Rio de Janeiro, Rua Jardim Botânico 1008, 22470-051, Rio de Janeiro, RJ. E-mail: marcia@jbrj.gov.br. ${ }^{3}$ Engenheiro Agrônomo, Professor Adjunto, PhD em Ciências do Solo, Departamento de Ciências do Solo, Instituto de Agronomia, UFRRJ. E- mail: berbara@ufrrj.br. 
liou-se a utilização de IgY para detecção de acetato de lupeol (LAc) (hapteno com peso molecular inferior a 500 daltons) em extratos metanólicos de Vernonia scorpioides Lam., Pers (Asteraceae).

\section{MATERIAL E MÉTODOS}

\section{Preparação de extratos de plantas}

Utilizou-se folhas e raízes de Vernonia scorpioides colhidas no campus da UFRRJ, e registradas no herbário RBR da UFRRJ sob o n 4140. Um grama de planta seca e granulada foi adicionada de $10 \mathrm{~mL}$ de metanol sob agitação em banho-maria a $60^{\circ} \mathrm{C}$. Cada extrato obtido foi filtrado e evaporado até atingir o volume de $1 \mathrm{~mL}$, dos quais $30 \mu \mathrm{L}$ foram utilizados para procedimentos de captura imunológica e quantificação imunoenzimática de LAc (WAGNER, BLADT, 2001).

\section{Preparo do conjugado hapteno-proteína}

Uma solução contendo $171 \mathrm{mgmL}^{-1}$ de LAc puro foi adicionada de igual volume de uma solução contendo $10 \mathrm{mgmL}^{-1}$ de BSA em tampão M.E.S. (0,1 M 2-N-morfolino-etanosulfonato, $0,15 \mathrm{M} \mathrm{de} \mathrm{NaCl}, \mathrm{pH} 4,7$ ), sob agitação constante. Acrescentaram-se $50 \mu \mathrm{L}$ de aldeído fórmico (Sigma Aldrich, USA) sobre a mistura que foi, em seguida, incubada sob agitação, em banho-maria a $56^{\circ} \mathrm{C}$ durante 24 horas, e dialisada a $4^{\circ} \mathrm{C}$ durante 72 horas contra $2 \mathrm{~L}$ de solução salina fosfatada (0,01M de NaHPO4 adicionado de $0,15 \mathrm{M}$ de $\mathrm{NaCl}, \mathrm{pH}$ 7,2) com três trocas diárias (MANNICH, 1912, ERLANGER, 1973, 1980, HERMANSON, 1996). O número de moles de LAc $(\mathrm{PM}=485.7244)$ por mol de BSA (PM = 67.000) foi estimado pelas concentrações molares relativas.

\section{Animais utilizados}

Foram utilizadas duas galinhas poedeiras White Leghorn, com 20 semanas de vida, pesando em torno de $1 \mathrm{~kg}$ (Setor de Avicultura do Instituto de Zootecnia da Universidade Federal Rural do Rio de Janeiro), mantidas em gaiolas individualizadas, recebendo água potável e ração de postura (Purina, Brasil) ad libidum. As amostras de ovos e de soros foram obtidas a cada sete dias, entre o dia da primeira inoculação e o sexagésimo dia de experimentação.

\section{Indução de anticorpos IgY anti Lac}

Pesou-se, 500 $\mu \mathrm{g}$ do conjugado BSA-LAc e fez-se uma emulsão em adjuvante completo de Freünd foram administrados por via subcutânea em duas poedeiras. As aves, então, receberam outras doses do conjugado BSA-LAc em adjuvante incompleto de
Freünd a cada intervalo de duas semanas: dois inóculos contendo $250 \mu \mathrm{g}$ e quatro inóculos contendo $100 \mu \mathrm{g}$ do conjugado imunogênico (FREIRE, 1994, WELZIG, 2003).

\section{Obtenção e purificação de anticorpos anti-LAc}

Diluiram-se $10 \mathrm{~mL}$ de gemas de ovos em $100 \mathrm{~mL}$ de água bidestilada estéril, acrescentando-se $10 \%$ (V/V) de sulfato de dextrana (PM inferior a 500.000, Sigma, USA) . A precipitação de globulinas foi realizada pela adição de igual volume de solução saturada de sulfato de amônia seguida de diálise do precipitado contra solução salina tamponada com fosfatos (PBS) $\left(0,01 \mathrm{M} \mathrm{KH}_{2} \mathrm{PO}_{4}, 0,01 \mathrm{M} \mathrm{Na}_{2} \mathrm{HPO}_{4}, 0,15 \mathrm{M} \mathrm{NaCl} \mathrm{pH} 7,4\right)$. A purificação de IgY foi completada através de cromatografia de troca aniônica seguida de gel-filtração em resina Sephadex G-25 (Sigma, USA) (POLSON, 1990). As frações de IgY anti-LAc foram obtidas por cromatografia de imunoafinidade, e as das IgY totais interagiram com LAc-BSA presos a resinas ativadas de CNBr-Sepharose(Pharmacia). Após incubação por $2 \mathrm{~h}$ à temperatura ambiente, as IgY com diferentes especificidades foram eliminadas por eluição PBS. As IgY anti-LAc foram, finalmente, recuperadas com glicina- $\mathrm{HCl}$ a $0,2 \mathrm{M}, \mathrm{pH} 2,8$ e dializadas contra PBS.

\section{Ensaio Imunoenzimáticos}

Em todos os ensaios de ELISA realizados, utilizou-se metodologia clássica, previamente descrita (HARLOW, LANE 1988, CROWTHER 1996). Microplacas de fundo chato contendo 96 orifícios (Nunc Immuno Maxisorp, Roche Diagnostics) foram sensibilizadas com LAc-BSA, ou com IgY anti-LAc (20 $\mathrm{mgL}^{-1}$ de proteínas, previamente diluídas em PBS $0,1 \mathrm{M} \mathrm{pH} 7,4)$ durante uma noite a $4^{\circ} \mathrm{C}$. As placas sensibilizadas foram lavadas com $200 \mu \mathrm{L}$ de PBS e adicionadas de $200 \mu \mathrm{L}$ por orifício de uma solução de soroalbumina BSA $\left(1 \mathrm{gL}^{-1} \mathrm{em} \mathrm{PBS}\right)$ e incubadas a $37^{\circ} \mathrm{C}$ por $2 \mathrm{~h}$. As placas sensibilizadas foram adicionadas de $100 \mu \mathrm{L}$ por orifício de soros (diluídos entre $10^{-1}$ e $10^{-12}$ ), ou de antígeno (diluído a 1:200), conforme o caso, novamente incubadas, lavadas e, posteriormente adicionadas de $100 \mu \mathrm{L}$ por orifício de 1:10.000 de IgY antiLAc, ou anti-IgY, marcados com peroxidase. Após a adição do sistema marcado, as placas foram novamente incubadas, lavadas e adicionadas de $200 \mu \mathrm{L}$ por orifício de uma solução de substrato $(0,01 \%$ de ortofenilenodiamina, $0,1 \mathrm{M}$ de $\mathrm{C}_{6} \mathrm{H}_{8} \mathrm{O}_{7} .1 \mathrm{H}_{2} \mathrm{O}, 0,1 \mathrm{M}$ de $\mathrm{Na}_{2} \mathrm{HPO}_{4} .2 \mathrm{H}_{2} \mathrm{O}, 004 \%$ de peróxido de hidrogênio, $\mathrm{pH}$ $5,0)$. A revelação do ensaio deu-se por desenvolvimento de cor após 15 minutos a temperatura ambiente, ao abrigo da luz e leituras de Absorvância a 492nm em leitor de ELISA (Titertek, USA). Foram feitas curvas 
de calibração para anticorpos utilizando-se parâmetros de regressão incorporados ao "software" Soft MAX Pro. Para os ensaios de quantificação, utilizaram-se calibradores e controles obtidos a partir de preparações contendo concentrações definidas de LAc purificadas segundo metodologia previamente descrita (PIETRZYK, FRANK, 1974). Observou-se, também, o efeito interferente da concentração final de metanol sobre o ensaio de IgY-ELISA. A reprodutibilidade (precisão) do método foi considerada como sendo o inverso da média do coeficiente de variação interna, tendo-se em conta 25 repetições para cada medida em amostras de calibradores contendo concentrações baixas, intermediárias ou elevadas de LAc, durante quatro dias consecutivos. As reações cruzadas foram estimadas de acordo com a concentração na qual a ligação IgY-LAc foi inibida pela adição de esqualeno, lupeol ou lanolesterol (Sigma, USA), em relação ao padrão de LAc, em, pelo menos, $50 \%\left(\mathrm{IC}_{50 \%}\right)$. O grau de recuperação analítica das IgY anti LAc, foi determinado através de três series de extratos metanólicos de Vernonia scorpioides $(n=30)$ contendo 50, 60 e 80 $\mathrm{mg} . \mathrm{mL}^{-1}$ de LAc, respectivamente. A recuperação analítica foi calculada como sendo a razão percentual entre as concentrações de LAc medidas e calculadas fisicoquimicamente.

\section{Análise estatística}

Utilizaram-se comparações múltiplas das medias através de ANOVA para comparação de amostras sem LAc, assim como de amostras contendo diferentes concentrações do triterpeno. Nos casos em que ficou demonstrada a significância estatística, utilizou-se o teste de Bonferroni, comparando-se múltiplos testes T entre os grupos. As correlações entre as diferentes dosagens de LAc e entre LAc e outros triterpenos (esqualeno, lupeol e lanolesterol) foram efetivadas por analises de regressão linear utilizandose "software" apropriado (Axum LE 2003).

\section{RESULTADOS E DISCUSSÃO}

Os triterpenos, como o esqualeno, o LAc e diversos compostos esteroidais com 30 átomos de carbono na sua estrutura principal, não são imunogênicos e podem ser encontrados em diversas espécies de microorganismos, algas, insetos e famílias de plantas, estando sempre relacionados a atividades biológicas relevantes (URICH, 1990). Estudos farmacobotânicos realizados com lupeol (L-OH) e LAc indicaram serem estes possuidores de ação antiinflamatória, anticancerígena, antibiótica e antimalárica e representam uma parcela significativa dos terpenos com atividade biológica presentes em Vernonia scorpioides (FREIRE et al., 1996, SING et al., 1997). No presente trabalho, reporta-se a aplicação do método de ELISA indireto para a detecção e quantificação de LAc, tal como realizado por CIBOTTI et al. (1990) que desenvolveram anticorpos monoclonais, oriundos de hibridomas murinos, para alcalóides da vinca. A diferença básica do procedimento presentemente descrito reside no fato de haver-se desenvolvido anticorpos em galinhas poedeiras (IgY) que, por conta da distância filogenética, são capazes de reconhecer determinantes antigênicos dificilmente reconhecidos por anticorpos de mamíferos (WELZIG, 2003). Além disso, as IgY são obtidas a partir da gema de ovos provenientes de poedeiras hiperimunizadas, sem que haja sacrifícios ou problemas de variações isotípicas (as IgY possuem um único isotipo) comumente encontrados em ensaios baseados em anticorpos de mamíferos (POLSON, 1990; FREIRE, 1994; HERMANSON, 1996; WELZIG, 2003). O acoplamento do hapteno a BSA (carreador) realizado originou o conjugado imunogênico LAc-BSA, com seis moléculas de LAc acoplados a cada molécula de BSA. O anticorpos IgY anti-LAc obtidos foram capazes de reconhecer tanto ao hapteno, quanto ao conjunto hapteno-carreador. Obteve-se, em média, $80 \mathrm{mg}$ de IgY-anti LAc por gema de ovo hiperimune processada. As reações cruzadas intrínsecas foram eliminadas pela passagem dos preparados em colunas de sepharose adsorvidas ao conjugado LAc-BSA. A interferência do carreador na determinação dos títulos de anticorpos anti-LAc foi completamente eliminada pela presença de BSA nas soluções de diluição e na etapa de bloqueio dos ensaios de ELISA. Os títulos de anticorpos anti-LAc presentes nas gemas corresponderam a $60 \%$ dos anticorpos recuperados, corroborando com POLSON (1990) e HERMANSON (1996) em estudos de obtenção de IgY para outros haptenos conjugados. Verificou-se que, tal como descrito anteriormente (WELZIG, 2003), a concentração de IgY foi crescente e estabilizou-se ao longo do segundo mês, equivalendo a $90 \%$ dos anticorpos circulantes das aves com as mesmas especificidades (Figura 1). Uma vez purificados, os anticorpos IgY obtidos foram utilizados para a elaboração do método de detecção do triterpeno em extratos metanólicos de V. scorpioides (Ig Y-ELISA anti LAc). As absorvâncias obtidas no IgY-ELISA anti-LAc foram inversamente proporcionais à concentração de LAc nas amostras. A curva de dose-resposta realizada pela associação das absorvâncias detectadas a 492nm e o logaritmo das concentrações de LAc contido nos diferentes calibradores utilizados apresentou forma sigmoidal tí- 


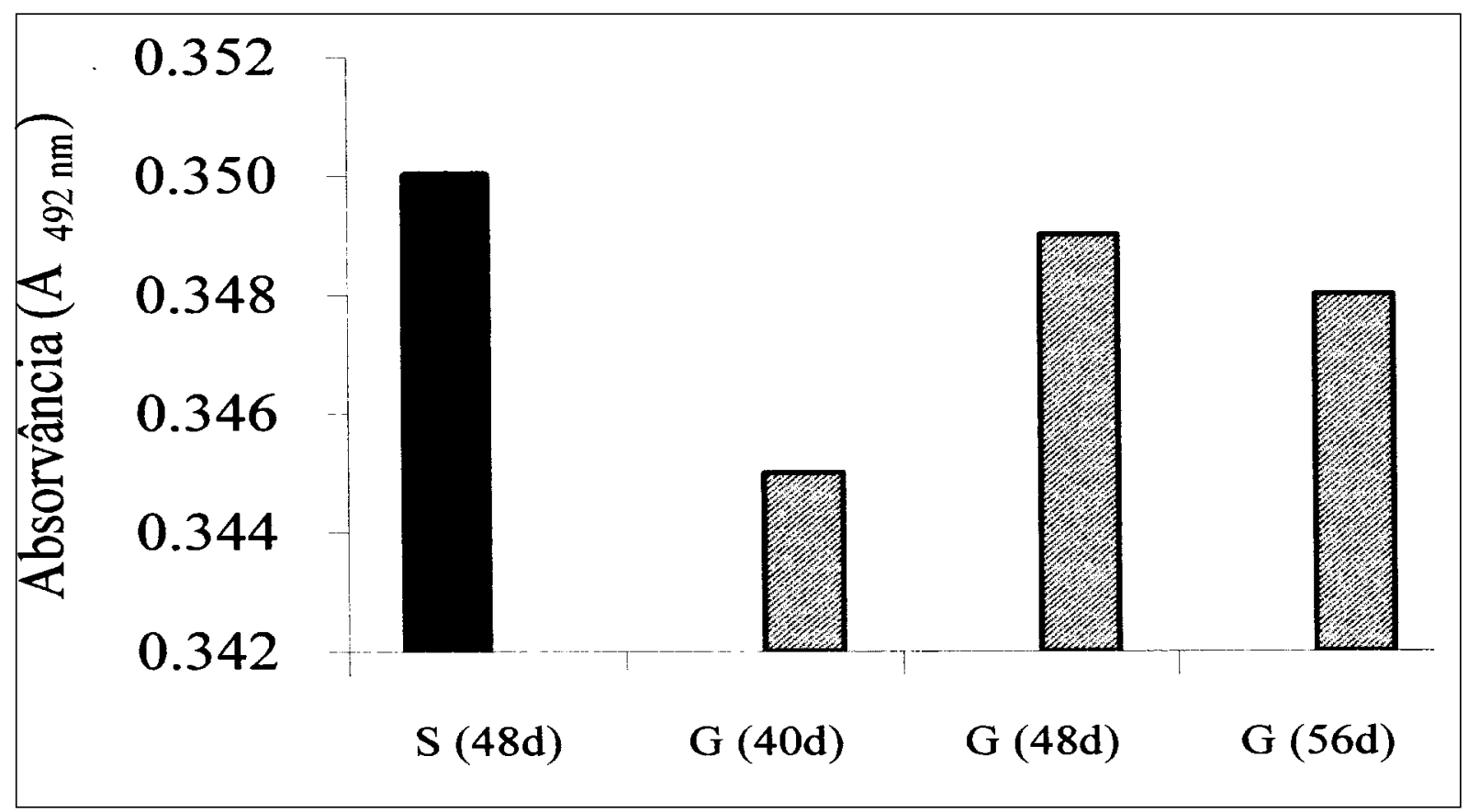

Figura 1 - Titulação através de ELISA de captura de anticorpos IgY anti-acetato de lupeol no soro (S), no $48^{\circ}$ dia (48d) e na gema de ovos (G), nos dias 40 (40d), 48 (48d) e 56 (56d), após inoculação de galinhas poedeiras com o conjugado imunogênico de soroalbumina bovina ligada a acetato de lupeol. A barra negra corresponde aos valores médios de anticorpos séricos e as barras acinzentadas às médias dos títulos de anticorpos IgY anti-acetato de lupeol contidos nas gemas em diferentes períodos de observação. $\mathrm{N}=21, \mathrm{p}<0,001$.

pica. Os resultados obtidos foram linearizados através de um programa logístico binário de transformações simples logit-log, originando uma relação diretamente proporcional entre a concentração de LAc em $\mu \mathrm{g} . \mathrm{g}^{-1}$ e as absorvâncias a $492 \mathrm{~nm}$. As análises foram validadas através de cromatografia líquida de alta eficiência (HPLC) e cromatografia gasosa acoplada a espectrógrafo de massa (CG/MS) (CONNORS, 1992), gerando coeficiente de correlação $\left(r^{2}\right)$ de 0,9956 . A faixa de linearidade foi obtida a partir da $\mathrm{IC}_{50 \%}$ estimada como sendo equivalente a $0,02 \mu \mathrm{gg}^{-1}$ de LAc. As variações de absorvância foram diretamente proporcionais a concentração de LAc na faixa entre $0,02 \mu \mathrm{g} \mathrm{g}^{-1}$ e $10 \mu \mathrm{g}$ $\mathrm{g}^{-1}$, respectivamente, consideradas como sendo os limites inferior e superior de detecção para o IgY-ELISA anti-LAc (Figura 2). A reação cruzada com diferentes terpenos não influenciou na qualidade dos valores de predição estabelecidos, por conta da pequena interferência que os mesmos ocasionaram (sempre inferiores a $0,02 \%$ ), mesmo quando adicionados em concentrações superiores a 100ppm (Tabela 1). A adição de L$\mathrm{OH}$ diminuiu em $10 \%$ a $\mathrm{IC}_{50 \%}$ para LAc quando as preparações de IgY foram adicionadas de $0,029 \mathrm{ppm}$ no extrato metanólico do vegetal (vmet-OH) e em $20 \%$ quando o mesmo triterpeno estava presente na concentração de 100 ppm. O parâmetro ajustável de positividade foi estabelecido entre 89,7 e $99,7 \%$, com especificidade de 99,8\%, na ausência de reações cruzadas significativas (Tabela 2). Os controles de reação constituídos de metanol PA confirmaram não haver influência desse constituinte na capacidade de captura de moléculas de LAc, corroborando com a literatura (FREIRE, 1994, CROWTER, 1995). O elevado fator de diluição utilizado tanto para anticorpos (1: 4000) como para os v-metOH (1:200), eliminou as possibilidades de interferências, decorrentes concentrações muito acima da linearidade alcançada pelo método, ou de reações cruzadas, que somente ocorrem quando há uma grande disponibilidade de anticorpos e (ou) antígenos, capazes de interferir na qualidade analítica do método (HARLOW \& LANE, 1988; CROWTER, 1995). A eficiência estimada do IgY ELISA anti LAc foi de 94,7\%, com coeficiente de variação interna de 4,22 $\pm 1,03 \%$, evidenciando uma reprodutibilidade entre $94,75 \%$ e $96,81 \%$. Por conta disso, pôde-se atestar a robustez do método IgY-ELISA anti-LAc, corroborando com trabalhos anteriores (FREIRE, 1994; HERMANSON, 1996; WELZIG, 2003), que ressaltam a utilidade da IgY para ensaios de detecção e purificação de haptenos de origem vegetal, ou animal, tornados imunogênicos através de conjugação com uma molécula carreadora. 


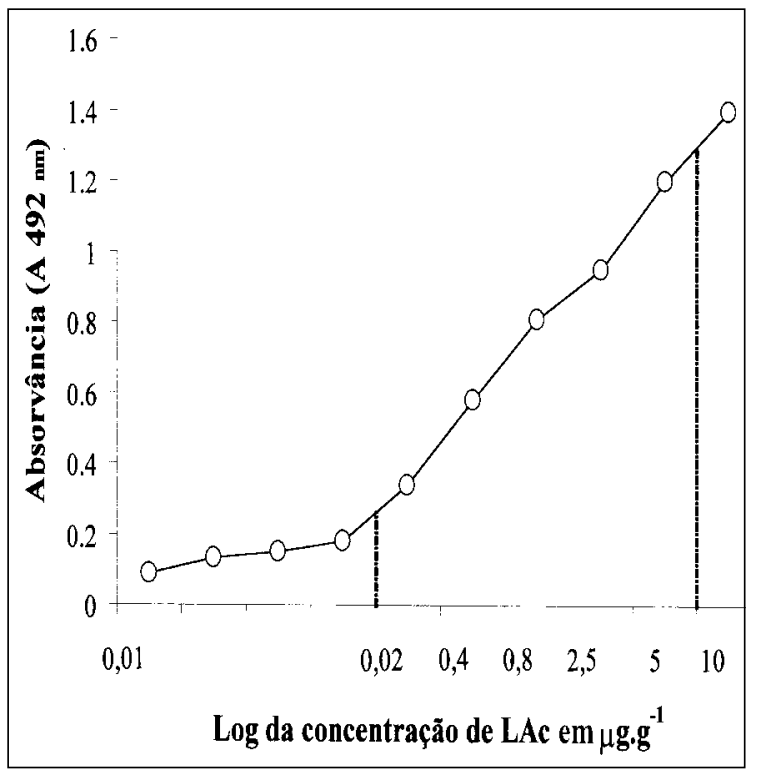

Figura 2 - Curva de calibração utilizada na quantificação de acetato de lupeol (LAc) através ELISA indireto. As absorvâncias a $492 \mathrm{~nm}$ foram relacionadas com valores em ppm. $\mathrm{mL}^{-1}$ correspondentes às diferenças entre as absorbâncias em extratos metanólicos de Vernonia scorpioides e o sistema branco (sem LAc). As linhas pontilhadas indicam os limites mínimo e máximo de detecção de LAc através de IgYELISA anti-Lac.

Tabela 1 - Medidas de especificidade do ensaio IgY-ELISA para acetato de lupeol em amostras de calibradores submetidas a adição de diferentes triterpenos capazes de ocasionar diminuição da $\mathrm{IC}_{50 \%}$. ELISA realizado com acetato de lupeol diluído a 1:200. Os resultados representam médias de quatro ensaios com três repetições, $\mathrm{p}<0,01$.

\begin{tabular}{lccccc}
\hline Triterpeno & Esqualeno & Lanosterol & Lupeol & $\begin{array}{c}\text { Acetato de } \\
\text { Lupeol }\end{array}$ \\
\hline $\mathrm{IC}_{50 \%}$ & $>100 \mathrm{ppm}$ & $>100 \mathrm{ppm}$ & $29 \mathrm{ppm}$ & $100 \mathrm{ppm}$ & $0,02 \mathrm{ppm}$ \\
$\begin{array}{l}\text { Reações } \\
\text { cruzadas }\end{array}$ & $<0,02 \%$ & $<0,02 \%$ & $10 \%$ & $<20 \%$ & $100 \%$ \\
\hline
\end{tabular}

Tabela 2 - Percentual de sensibilidade do ensaio IgY-ELISA antiacetato de lupeol em amostras associadas das partes aérea (PA) e radicular (PR) de Vernonia scorpioides com teores conhecidos (valor calculado) de acetato de lupeol, nas proporções de $1 / 1 ; 1 / 5 ; 2 / 4$; e $5 / 1$, respectivamente. Resultados expressos em ppm, $\mathrm{p}<0,001$.

\begin{tabular}{lcccc}
\hline & PA / PF & 1PA / 5PF & 2PA / 4PF & 5PA / 1PF \\
\hline Valorcalculado & 62 & 103,5 & 93 & 78 \\
IgY-ELISA & 60 & 103,2 & 88 & 70 \\
Sensibilidade & 96,8 & 99,7 & 94,6 & 89,7 \\
\hline
\end{tabular}

\section{CONCLUSÃO}

O método de IgY ELISA anti-LAc, além de ser mais simples e econômico do que hibridomas, pode tornar os ensaios de detecção imunológica de micromoléculas mais precisos que os métodos convencionais, prestandose para detectar e quantificar moléculas naturais não imunogênicas (haptenos) em extratos de plantas. A grande reprodutibilidade do método, assim como a sensibilidade superior a $90 \%$, indica-o para análises em quantidades reduzidas de material vegetal, possibilitando amostragens mais realistas e estatisticamente significativas.

\section{AGRADECIMENTOS}

$$
\text { Apoio do CNPq - Projeto } \mathrm{n}^{\mathrm{o}} \text { 305370088-0. }
$$

\section{REFERÊNCIAS BIBLIOGRÁFICAS}

CIBOTTI, M. C. et al. Monoclonal antibodies to bis-indole alkaloids of Catharanthus roseus and their use in enzyme-linked immunosorbent-assays. Phytochem, V.29, n.7, p.2109-2114, 1990.

CONNORS, K.A. A textbook of pharmaceutical analysis. USA : John Wiley \& Sons, 1982. 664p.

CROWTHER, J. Methods in molecular biology: ELISA theory and practice. USA : Humana, 1995. V.42, 223p.

ERLANGER, B.F. Principles and methods for the preparation of drug protein conjugates for immunological studies Pharmacol Rev, v.25, p.271-280, 1973.

ERLANGER, B.F. The preparation of antigenic haptencarrier conjugaters: a survey. Meth Enzymol, v.70, p.85103,1980 .

FREIRE, M.F.I. et al. Inhibition of fungal growth by extracts of Vernonia scorpioides (LAM) Pers. Rev Bras Microbiol, São Paulo, v.27, n.1, p.1-6, 1996.

FREIRE, R.B. Possibilidades y limites para el diagnóstico inmunológico de las micotoxicosis. In: CRUZ, L.C.H. Mycotoxinas: perspectiva latioamericana. Seropédica : EDUR UFRRJ, 1994. p.23-28.

HARLOW, E., LANE, D. Antibodies: a laboratory manual USA : Cold Spring Harbor Laboratory, 1988. 956p.

HERMANSON, G.T. Bioconjugate techniques. USA : Academic, 1996. 785p,

MANNICH, C.; KROSCHE, W. Uber ein Kondesationproduckt aus formaldeyde, Ammoniak und Antipyrin. Arch Pharm, v.250, p.647-667, 1912.

PIETRZYK, D.J.; FRANK, C.W. Analytical chemistry: PolSON A. Isolation of IgY from the yolks of eggs by chloroform polyethylene glycol procedure. Immunol Invest, v.19, p.253-258, 1990.

SING, S. et al. Anti-inflammatory activity of lupeol. Fitoter, v.68, n.1, p.9-15, 1997. 
URICH, K. Comparative animal biochemistry. Berlin : Springer-Verlag, 1990. 782p.

WAGNER, H.; BLADT, S. Plant drug analysis: a thin layer chromatography atlas. 2.ed. Berlin : Springer Verlag, 2001. 384 p.
WELZIG, E. Studie ueber das pontential von immunoanalytischen methoden fuer die organische spurenanalytik auf der basis von eidotterantikoerpern. 2003. 145f. Tese (Doutorado em biotecnologia) - Technische Universitaet Wien.

Ciência Rural, v.34, n.4, jul-ago, 2004. 